The Research Journal of the Costume Culture

[Original Article]

Received January 11, 2017

Revised March 11, 2017

Accepted March 15, 2017

${ }^{\dagger}$ Corresponding author

(coco7@cbnu.ac.kr)

ORCID

Jiyoung Kim

http://orcid.org/0000-0003-0184-5374

This work was supported by the Ministry of Education of the Republic of Korea and the National Research Foundation of Korea

(NRF-2016S1A5A2A01023562).

\section{Iconological analysis on imaginary animals in traditional culture \\ - Focused on four auspicious animals(四靈獸) in Korean folk paintings -}

\author{
Ji Young Kim ${ }^{\dagger}$ \\ Dept. of Fashion Design Information, Chungbuk National University, Korea

\section{전통문화에 수용된 상상 동물의 도상해석학적 분석 - 사령수(四靈獸) 민화를 중심으로 -}

\author{
김 지 영 $^{+}$ \\ 충북대학교 패션디자인정보학과
}

\begin{abstract}
The purpose of this study is to apply iconology to discover the symbolic system of imaginary animals focused on four representative auspicious animals in Korean folk paintings. Study methods included literature review of folk paintings, iconological analytics books, and articles. A total of 16 folk paintings of four auspicious animals in the Joseon Dynasty were analyzed using Panofsky's iconology. The four auspicious animals were Yong(dragon), Bonghwang(the eastern version of the phoenix), Shingoo (divine turtle), and Kirin(one-horned combination of a dragon and horse). According to iconological analysis, Yong is a typical symbol of royal authority, a deity of water as an object of respect with a remarkable talent of transformation, and in iconographical interpretation, represents reverence for transcendent power. Bonhwang is the symbol of a king, sun worship, the emblem of nobility and integrity, and in iconographical interpretation, the psychic bing in the sky. Shingoo is fortune prophecy, longevity and immortality, an envoy of deity, and according to iconographical interpretation, the organic view of the world. Kirin is a divine benign creature, a symbol of talent and honor, mediator between sky and earth, and in iconographical interpretation, an expression of Confucian ideology. This study produced three results. First, the four auspicious animals projected the human hope to overcome human limitations through divine creatures with mythical abilities. Second, they reflected everyday common hopes and values of pursuing fortunes and happiness. Third, the four auspicious animals' iconology was not independent of each other; it seemed to be common to and combined with each other.
\end{abstract}

Keywords: folk paintings(민화), four auspicious animals(사령수), Panofsky(파노프스 키), iconology(도상해석학), imaginary animals(상상의 동물) 


\section{Introduction}

전통문화는 공통의 관심사나 취향을 토대로 공동 체의 고유한 미적 감흥과 미의식을 표현한다. 민화(民 畫)는 민족의 의식과 감정이 투영된 그림으로 서민의 미의식이 깃든 중요한 문화유산이라 할 수 있다 (Chung, 2011a). 민화의 아름다움은 세계 속에 우리 문화를 알리고, 그 가치를 인정받을 수 있는 충분한 가능성을 지니고 있으며, 디자인 분야의 새로운 접근 을 위하여 조명할 무궁무진한 가치가 있다.

본 연구는 민화의 다양한 화제(畫題) 중 길상의 의 미가 있는 상상 동물을 대상으로 한다. 인간은 예부 터 동물에 대한 상징을 통해 벽사, 장수, 부귀, 출세 등 삶에 대한 염원을 표현하였으며, 여기에 점차 상 상력이 더해져 상서로운 상상의 동물이 탄생하게 되 었다(Yun, 2010). 상상 동물 중 동양 문화권에서 특히 중요하게 여겨진 네 마리의 동물을 사령수(四靈獸)라 하는데, 이는 곧 용, 봉황, 신구, 기린을 말한다. 사령 수는 고대 중국에서부터 영험한 동물로 알려졌으며, 우리나라에 수용되면서 여러 설화와 민담에서 역시 신령한 존재로 그려졌다. 사령수는 상상 속의 신비로 운 동물로 인간을 능가하는 힘에 대한 선망과 두려움 이 투사된 존재이다.

상상 동물은 인간의 이상 속에서 만들어진 도상으 로 그 상징성과 내적 의미를 파악하는데 있어 도상학 적 해석이 가능하다. 도상학은 자료를 수집, 분류하 고, 모티브의 해석을 통해 도상을 분석하는 방법을 제시하며, 그림의 일화와 알레고리의 분석을 통해 해 석학적으로 예술 분야를 통합한다(Kim, K. E., 2009).

특히 에르빈 파노프스키(Erwin Panofsky)가 제시 한 도상학의 해석 틀은 인문학적 관점에서 예술작품 의 의미를 접근할 수 있게 하였고, 미술사학의 분야 에서 확고한 패러다임을 형성하였다. 예술이 지닌 사 실적, 표현적 의미는 모두 역사적, 사회적 제약 안에 서 해석된다는 그의 이론은 전통 기층문화로서 민화 의 표현적 의미를 역사적, 사회적 관점에서 해석하고, 인문학적 토대 위에 민화를 재조명할 수 있는 계기를 마련해 주었다.

본 연구의 목적은 문화적 함의가 포함된 패션문화 상품의 디자인 개발을 위한 기초연구로 민화에 등장 하는 상상 동물 중 대표적인 사령수를 중심으로 도상
해석학적 분석을 통해 내재되어 있는 함축적인 의미 를 파악하고, 사회, 문화와 예술미에 대한 사적 고찰 과 분석 과정을 거쳐 상징체계를 밝히는 것이다.

연구방법으로는 민화와 파노프스키 도상해석학에 대한 단행본 서적과 선행연구를 통해 문헌고찰을 실 시한 후, 파노프스키의 도상해석학을 토대로 조선시 대 사령수 민화를 분석하였다. 자료의 분석은 본 연 구자와 민화 연구가 1 인, 의류학 전공 박사과정 2 인 이 조선시대 민화 화보집에서 용, 봉황, 신구, 기린의 표현이 보편적, 일반적이라고 판단한 민화 각각 4점 씩 총 16점을 선정하여 파노프스키 도상해석학의 세 가지 단계를 적용하여 분석하였다. 도상해석학적 분 석을 위해 민화 전문가로 잘 알려진 김영재, 윤열수, 정병모, 허균 등의 민화 관련 서적과 우리나라 전통 설화집 및 동양문화, 사상, 철학 관련 서적 등을 참고 하였다. 파노프스키의 도상해석학을 통해 상상 동물 과 그와 관련된 상징체계를 이해하는 것은 전통문화 컨텐츠를 인문학적 관점에서 심층 분석하여 전통문 화의 맥락과 상징성을 이해하는데 도움을 줄 것이다.

\section{Theoretical Background}

\section{Theoretical background of iconology}

\section{1) Idea of iconography and iconology}

도상학(iconography)과 도상해석학(iconology)은 도 상(icon)이 지니는 의미내용을 중심으로 대상과 그 의 미와의 관계를 연구하는 학문이다(Lee \& Geum, 2008). 미술사에서 도상학은 작품의 의미나 모티브를 다루 는 분야로 17 19세기에 특히 발전하였으며, 기독교 미술의 상징성이나 바로크 미술의 복잡한 우의도(寓 意圖)에 이르기까지 동일주제에 대한 도상의 지역적. 역사적 변화 등을 다루었다("Iconography", n.d.). 20 세기 무렵 등장한 도상해석학은 도상학에서 발전하 여 도상의 본질적 의미를 해석하고, 그 내용과 형식 간의 관계를 연구하는 미술사의 연구방법이라 할 수 있다.

도상학은 그림에 그려진 도상을 통해 그 의미를 찾 아내며, 주제의 확인을 목적으로 하는 서술적 방법을 취한다. 도상학적 연구는 성서나 신화, 역사적 사건 등의 사실내용을 문헌 텍스트를 통해 간접적으로 확 
인하고, 확인된 내용을 조형 작품과 맞추어 보면서 문헌에 기록된 주제 모티프와 조형작품에 재현된 내 용이 일치하는지를 비교한다(Kaemmerling, 1979/ 1997). 그러나 작품을 분석적으로 다루거나 해석하는 작업은 도상학적 작업에서 하지 못한다. 반면, 도상해 석학은 작품에 표현된 상징이나 의미작용 등을 파악 하는 것이 주된 목적으로, 찾아낸 의미를 가지고 그 시대 혹은 작가에 대한 전체적인 상황을 유추, 해석 해 내는 분야라 할 수 있다(Jo, 1997). 즉, 도상해석학 은 좀 더 거시적 관점에서의 작품해석을 시도하는 것 으로 여러 시대에 등장하는 문헌들을 토대로 한 대상 이 어떤 의미내용을 지니고 있는지, 그 의미내용이 다른 요소와 결합하여 어떻게 의미가 확장되고 있는 지 의미적 상관관계를 토대로 작품을 해석하는 것이 다.

도상해석학의 기초를 다진 바르부르크(A. Warburg, 1866 1929)는 문화학 연구의 한 갈래로 도상해 석학의 개념을 도입하였다. 그는 르네상스 미술에서 고대의 양식적 영향이 무엇인지 분석하면서 시각 유 산을 문화학적으로 이해하는 수단으로 삼았다 (Kaemmerling, 1979/1997). 그는 기존의 종교미술 위 주의 연구에서 벗어나 다양한 학문과 미술의 관계에
대한 연구로 도상해석학을 발전시켰고, 기존 도상학 적 관점과의 차별성을 강조하면서 도상해석학적 방 법을 통해 얻어지는 해석학적 기초를 강조하였다.

바르부르크 이후 에르빈 파노프스키(Ervin Panofsky, 1892 1968)는 르네상스 미술을 해석하면서 도상 해석학의 해석 틀을 제시하여 학문적 이론으로 결실 을 맺었다. 그는 도상해석학을 도상학의 성과를 해석 학적으로 적용하는 것으로 보았고, 종합에 근거한 해 석방법이라 하였다(Panofsky, 1939/1972). 그는 복잡 하게 얽혀있는 조형작품 속의 의미를 명료하게 구분 하여 학문적으로 접근할 수 있는 길을 열어 주었다. 그의 이론은 미술사학의 분야에서 하나의 확고한 패 러다임이 되어 시각 문화 연구 분야에 큰 영향을 미 쳤으며, 회화, 건축, 영화이론 등의 연구에 있어 다방 면에서 활용되고 있다(Lim, S., 2012).

\section{2) Strata of Erwin Panofsky's Iconology}

파노프스키는 〈Table 1〉과 같이 도상학을 세 개의 층위로 의미단계를 구분하였다. 그는 종래의 도상학 에 정신적 해석을 도입하였고, 도상의 우의성을 초월 하여 존재하는 본질을 통해 미술품을 문화사적인 폭 넓은 이해 속에서 체계화시켰다(Kaemmerling, 1979

<Table 1> Strata of Erwin Panofsky's iconology

\begin{tabular}{l|l|l|l}
\hline \multicolumn{1}{c|}{ Object of interpretation } & Act of interpretation & \multicolumn{1}{c}{$\begin{array}{c}\text { Equipment for } \\
\text { interpretation }\end{array}$} & $\begin{array}{c}\text { Controlling principle of } \\
\text { interpretation }\end{array}$ \\
\hline $\begin{array}{l}\text { I_Primary of natural } \\
\text { subject matter-(A) factual, } \\
\text { (B) expressional-, } \\
\text { constituting the world of } \\
\text { artistic motifs. }\end{array}$ & $\begin{array}{l}\text { Pre-iconographical } \\
\text { description(and pseudo- } \\
\text { formal analysis) }\end{array}$ & $\begin{array}{l}\text { Practical experience } \\
\text { (familiarity with objects } \\
\text { and events) }\end{array}$ & $\begin{array}{l}\text { History of style(insight into the } \\
\text { manner in which, objects and } \\
\text { events were expressed by forms) }\end{array}$ \\
$\begin{array}{l}\text { II_Secondary or } \\
\text { conventional subject matter, } \\
\text { constituting the world of } \\
\text { images, stories and } \\
\text { allegories. }\end{array}$ & $\begin{array}{l}\text { Iconographical analysis } \\
\text { in the narrower sense of } \\
\text { the world }\end{array}$ & $\begin{array}{l}\text { Knowledge of literary } \\
\text { sources (familiarity with } \\
\text { specific themes and } \\
\text { concepts) }\end{array}$ & $\begin{array}{l}\text { History of types (insight into } \\
\text { the manner in which, under } \\
\text { specific themes or concepts } \\
\text { were expressed by objects and } \\
\text { events) }\end{array}$ \\
\hline $\begin{array}{l}\text { III_Intrinsic meaning or } \\
\text { content, constituting the } \\
\text { world of 'symbolical' } \\
\text { values. }\end{array}$ & $\begin{array}{l}\text { Iconographical } \\
\text { interpretation in a } \\
\text { deeper sense } \\
\text { (Iconographical } \\
\text { synthesis) }\end{array}$ & $\begin{array}{l}\text { Synthetic intuition } \\
\text { conditioned by personal } \\
\text { psychology and } \\
\text { 'Weltanschauung' }\end{array}$ & $\begin{array}{l}\text { History of cultural symptoms of } \\
\text { symbols' in general (insight into } \\
\text { the manner in which, under } \\
\text { tendencies of the human mind } \\
\text { were expressed by specific } \\
\text { themes and concepts) }\end{array}$ \\
\hline
\end{tabular}

From. Panofsky. (1939/1972). pp. 14-15. 
/1997). 그는 세 개의 의미단계는 예술작품에 접근하 기 위한 방법으로 단계별로 독립된 카테고리가 아니 라 서로 유기적인 과정으로 이해해야 한다고 하였다.

\section{(1) First stratum ; Pre-iconographical description}

첫 번째 단계인 전 도상학적 기술(記述)은 작품의 형식을 인지하는 단계로 다시 사실의미와 표현의미 로 나뉜다. 순수한 형태들이 어떤 대상을 그려내고 있는지 작품의 조형적 형태를 살핀 후 특정 형태를 만들어 냄을 확인하는 작업이며, 이를 통해 표현하는 의미가 무엇인지 파악하는 단계이다(Hyun, 2013). 즉, 형태분석의 단계로 선과 색면들이 어떤 재료로 특정 모티프의 형태를 만들어내는지 파악하고, 이 형 태들이 어울려 어떤 의미를 표현하는지 찾아내는 과 정이다(Panofsky, 1939/1972). 이러한 순수한 형태의 세계는 곧 예술적 모티브의 세계이며, 예술적 모티브 를 나열하는 일이 전 도상학적 단계에 해당된다.

\section{(2) Second stratum ; Iconographical analysis}

통상 도상학의 학문 범주에 속하는 좁은 의미의 도 상학적 분석단계로 이차적, 관습적 주제에 대한 인식 에 해당된다. 작품의 주제와 상징, 알레고리를 파악하 는 단계로 문헌의 원천과 주제에 대한 지식을 갖추고 있어야 한다(Kim, K. E., 2009). 즉, 형태와 양식들의 원인이 되는 관습과 이념을 도출하는 과정으로(Lee \& Geum, 2008), 그림의 이야기나 알레고리가 '의미' 가 되기 때문에, 해석자는 이에 대한 문헌지식이 필 요하다. 문헌자료를 통해 나타나는 관념과 테마를 토 대로 예술적 모티브와 이 모티브가 만들어내는 구성 물을 한편에, 또 작품의 주제성이나 구성의도를 다른 한편에 두어 양자를 연결하면서 이차적 주제를 파악 한다.

(3) Third stratum ; Iconographical interpretation 인문학적 시각에서 작품의 본질적인 혹은 숨어있 는 의미를 파악하는 도상해석학적 해석 단계로 작품 발생환경을 이루는 시대, 계급, 종교적 교리와 철학적 확신에 대한 이해와 주제가 작품화의 과정을 거치면 서 드러나는 숨은 원칙을 밝히는 최종적인 단계이다. 특히 '상징'의 가치들을 파악하고 해석하는 것이 목 표로 주관적인 직관이나 경험의 오류를 피하기 위해
문화적 징후의 역사와 보편적 의미의 상징을 분석하 고, 서로 다른 역사적 조건 가운데 어떤 방식으로 특 정 주제로 표현되는가를 관찰하여야 한다(Panofsky, 1939/1972). 이 단계에서 내재적 의미는 인간 내면의 본질적인 경향으로 상징적 가치에 해당하며, 구체적 인 예술작품들은 상징적 가치를 드러내는 징후라 할 수 있다(Lee, E. J., 2012). 깊은 의미에서의 도상학으 로 종합적 직관에 의해 구현되는 해석방법이다.

\section{Cultural meaning of imaginary animals}

상상 동물은 현실세계에 실존하는 동물이 아니라, 상상에 의해 만들어진 동물이다. 인간들은 오랜 역사 동안 각자의 염원과 상상력을 동원하여 상상의 동물 을 만들어내었다(Kang, 2015). 상상력에 의해 창조된 동물은 초자연적인 힘을 가지고 우주의 질서 속에서 각 영역을 담당하는 것으로 여겨졌다(Yun, 2010).

동서양의 신화에서 동물의 신화적 상상력은 매우 보편적인 문화 현상이다. 들뢰즈와 가타리는 바깥으 로의 이행을 '되기' 즉 생성으로 부르고 있다. '되기' 란 말 그대로 주체가 자신을 넘어서 다른 존재에 근 접해지는 것이다. 신화의 동물 이야기는 동물-되기라 고 할 수 있는데(Yu, Nahm, \& Pyo, 2015), 이는 동물 의 신체적 감응을 만들어낼 수 있는 힘과 속도를 인 간의 신체에 부여하는 것을 말한다.

상상의 동물은 현세 삶에 대한 갈망이 자연의 동물 에 표현되고, 여기에 상상력이 더해지면서 상서로운 서수(瑞獸)의 이미지로 나타난다(Yun, 2010). 상상 속 의 상서로운 동물을 그린 그림을 영수도(靈獸圖)라 하 는데, 상상 동물들은 대중의 생활 문화가 파생되는 과정에서 독창적인 상상력을 바탕으로 기발한 이야 기로 등장한다.

상상 동물은 동서양을 막론하고 실재하는 동물에 상상적 요소가 첨부되기도 하고, 여러 동물이 조합되 어 만들어지거나 혹은 온전히 상상만으로 새로운 동 물이 탄생하기도 한다. 특히 많은 상상 동물이 여러 동물들의 신체를 합성하여 만든 형태를 보이는데, 이 는 인간의 이상 속에서 만들어진 도상이 길상 사상과 결합하여 나타나기 때문이다(Takerube, 1988/2000).

같은 상상 동물이라도 시대와 지역에 따라 상징의 미가 달라지고 표현방법에도 차이가 있다. 문화권에 따라 상상 동물은 극명한 차이를 보이기도 한다. 용 
을 예로 들자면, 동양에서의 용은 권력, 왕을 상징하 는 상서로운 존재이자 신앙의 대상이지만, 서양에서 는 물리쳐야 하는 악의 존재이자 암흑세계의 동물로 그려진다(Yun, 2010).

상상 동물은 건국신화에 종종 등장하여 권력자의 정통성을 강조하기 위한 상징으로 나타난다. 또한 이 상향에 대한 동경을 배경으로 한 신비로운 존재로 그 려지기도 하는데, 고구려 고분 벽화 속의 사신도가 대표적이다. 고구려인들은 사후 세계의 환생을 믿으 며, 무덤의 사방에 강력한 수호의 힘을 가진 동물을 표현하였다(Lim, S.-M., 2012).

우리나라 전통의 상상 동물은 중국으로부터 영향 을 받은 경우가 많다. 상상 동물을 집대성한 중국의 문헌으로는 '산해경(山海經)'과 '삼재도회(三才圖會)' 가 있는데, 산해경은 중국 주변의 각 지역에 대한 인 문 지리서이자 신화집이며, 중국 고대 신화와 전설의 모체라 할 수 있다(Lim, S.-M., 2012). 산해경에 나타 나는 상상 동물은 두세 가지 이상의 동물이 혼합된 모습을 하고 있으며, 이로 인해 더욱 다양하고 강력 한 힘을 지닌 존재로 그려지고 있다.

이처럼 상상 동물은 초월적인 힘을 지니거나 상서 로운 존재로 그려지며, 인간의 잠재된 의식을 투영한 다. 상상 동물의 형상과 그에 내재된 상징성은 정신 적, 문화적 배경에 기인하며, 현세의 염원과 꿈이 담 겨 있다. 길상의 의미가 있는 상상의 동물은 실제와 허구의 경계선에서 끊임없이 인간의 호기심을 자극 하는 존재이다.

\section{Concept of four auspicious animals}

사령수는 이 세상 동물들의 우두머리로 간주되었 던 네 가지 영수(靈獸)로 용, 봉황, 신구, 기린을 말한 다. 중국 고대 유가 경전인 예기(禮記)의 예운(禮運)편 에 기록되어 있는데, 시대가 평안하고 좋은 일이 있 을 때 나타나는 서수(瑞獸)로 여겨진다(Takerube, 1988/2000). 용은 물고기처럼 비늘을 지닌 린충(鱗蟲) 의 우두머리, 봉황은 새처럼 날개를 가진 우충(犲蟲) 의, 신구는 갑각류처럼 딱딱한 껍질이 있는 갑충(甲 蟲)의, 기린은 털을 지닌 모충(毛蟲)의 우두머리로 보 았다(Kusano, 1997/2001).

사령수 중 가장 으뜸은 용으로 중국 전한시기의 회 남자(淮南子)에서는 ‘조류, 수류, 어류, 갑각류의 모든
동물은 용을 조상으로 한다'라고 했다(Heo, 2006). 우 리나라에서도 사령수 중용을 가장 최고로 쳤으며, 상 상의 동물이지만 마치 실존 동물로 착각될 만큼 친근 한 존재로 여겨졌다. 실제로 '삼국사기', '삼국유사', '세종실록지리지' 등에 용과 관련된 설화가 86편이나 기록되어 있다(Chung, 2011b). 비를 내리게 하고 제 왕을 상징하기도 하며, 불교에서는 호불신으로 여겨 지기도 한다(Yun, 2010).

봉황은 날개를 지닌 새들의 우두머리이다. 산해경 (山海經)에 의하면 “단혈산의 어떤 새가 생김새는 닭 과 비슷하며, 오색으로 무늬가 있는데, 그 이름을 봉 황이라 한다(Kang, 2015)"고 하였다. 이 새의 머리 무 늬는 덕을, 날개 무늬는 의를, 등의 무늬는 예를, 가슴 의 무늬는 인을, 배의 무늬는 신을 나타낸다(Kang, 2015). 우리나라에서는 삼국시대부터 봉황과 관련된 기록이 보이며 조선시대에는 예복이나 장신구, 공예 품 등에 사용되었고, 현재에도 대통령의 전용 휘장으 로 사용된다(Park, 2010).

신구는 갑충(甲蟲)의 우두머리로 신령스러운 거북 을 말한다. 사령 중 유일하게 거북이라는 실존 동물 을 근거로 하며, 여기에 상상의 요소가 더해진 동물 이다. 서기(瑞氣)를 내뿜고 있거나, 현무나 혹은 용과 비슷한 모습으로 표현되는 경우가 많아 실재하는 동 물이라기보다는 상상 동물의 성격을 보인다. 신구는 충분한 영양분을 체내에 보존할 수 있는 습성으로 인 해 천세, 만세까지 장수하는 신비한 능력을 가지고 있다고 전한다.

기린은 털이 있는 땅 짐승을 대표하는 상상의 동물 로 수컷을 기(麒), 암컷을 린(麟)이라 한다. 서양의 유 니콘에 해당하는 동양의 일각수로 이마에 뿔이 하나 있지만 그 끝에 살이 있어 다른 짐승을 해치지 않으 며, 생물을 아껴 풀도 밟지 않는 매우 인자한 동물로 그려진다. 기린이 나타나면 어진 성왕(聖王)이 나와 왕도를 펼 길조라고 하였고 태평성대가 온다고 하였 다(Lee, 2000).

사령수는 오행사상에서 비롯하여 인간사의 길상을 기원하려는 사람들에 의해 널리 유포되었다(Kim, 2015). 영수, 서조 사상은 초복벽사 사상, 영혼과 내 세에 관한 사상과 관련하여 크게 위세를 떨쳤으며, 세월이 지남에 따라 상상 동물의 영혼(靈)이 인간의 운수와 길흥에 관여한다고 믿게 되었다. 
중국에서는 사령수가 고분벽화나 묘실, 궁전 등에 자주 사용되었고, 천년을 사는 성스러운 짐승으로서 나라의 길흉을 미리 알려준다는 도교사상과 결부되 어 성행하였다. 우리나라에서도 삼국시대부터 고분벽 화 등에 사령무늬가 나타나며, 고려시대의 상형청자 (象形靑瓷)에 부분적으로 나타난다. 조선시대에 와서 는 새해를 축복하는 뜻으로 그린 세화(歲畫)에 등장 하기도 하며 각종 공예의장의 무늬로 활용되었다 ("Four auspicious animals pattern", n.d.).

\section{Iconological Interpretation of Four Auspicious Animals}

\section{Yong(龍)}

\section{1) Pre-iconographical description}

용의 형태에 대한 문헌기록에서 중국 후한 시대 왕 부(王符)는 머리는 뱀, 뿔은 사슴, 눈은 토끼, 귀는 소, 목은 뱀, 배는 조개, 비늘은 잉어, 발톱은 매, 발바닥 은 호랑이를 닮았다고 기록하였다(Chung, 2011a). 위 시대의 자전인 광아(廣雅)에서는 왕부의 내용 중 머 리가 낙타로 바뀐 것 외에는 동일하였고, 명대의 '본 초강목(本草綱目)'에서는 왕부의 내용과 동일하게 기 록되어 있다. 이처럼 용은 날짐승, 들짐승, 물짐승의 복합적인 형태로 여러 동물이 지닌 최대 강점만을 모 은 형상을 보인다(Yun, 2012).

민화의 용은 많은 경우 구름과 같이 나타나며, 용
솟음치듯이 유동적인 곡선을 보여준다. 역동적으로 굽이치는 형상으로 표현되며 신령한 보물 구슬인 여 의주가 함께 그려진 경우가 많다. 많은 경우, 더듬이 가 좌우로 뻗어 있으며 불꽃이 휘날리는 여의주를 삼 키려고 하는 모습으로 표현된다(Table 2).

\section{2) Iconographical analysis}

\section{(1) Symbol of royal authority}

용은 바다와 땅, 하늘을 자유롭게 넘나들 수 있는 가장 강력한 존재이며, 최고의 권력을 상징한다. 용이 왕권을 상징하기 시작한 것은 중국 진시황때부터라 고 전해진다. 진 이전의 주나라가 음양오행사상에서 화(火)에 해당하므로 수(水)를 상징하는 용으로 주의 권위를 압도하고자 한 것에서 유래하였다고 본다 (Chung, 2011a). 우리나라에서도 삼국시대부터 건국 신화에 용이 출현하여 왕권의 정당성을 보여준 사례 를 볼 수 있다. 고구려 건국신화에서 천신 해모수의 수레를 끈 것이 오룡(五龍)이며, 신라 혁거세의 왕비 알영을 낳은 계룡(鶏龍), 백제 무왕의 아버지는 지룡 (池龍)이었다(Jo, 2006). 고려를 세운 왕건의 할머니 또한 용이었고, 조선을 세운 태조 이성계도 출생담에 용을 내세워 자신의 혈통이 용에서 출발하고 있음을 강조하였다.

용이 왕을 상징한다고 보는 이유는 용에게 인간과 국가를 보호하고 물을 다스리는 능력이 있다고 믿었 기 때문이다(Yun, 2012). 왕의 얼굴을 용안(龍顔), 왕

$<$ Table 2> Analysis object of folk paintings on Yong

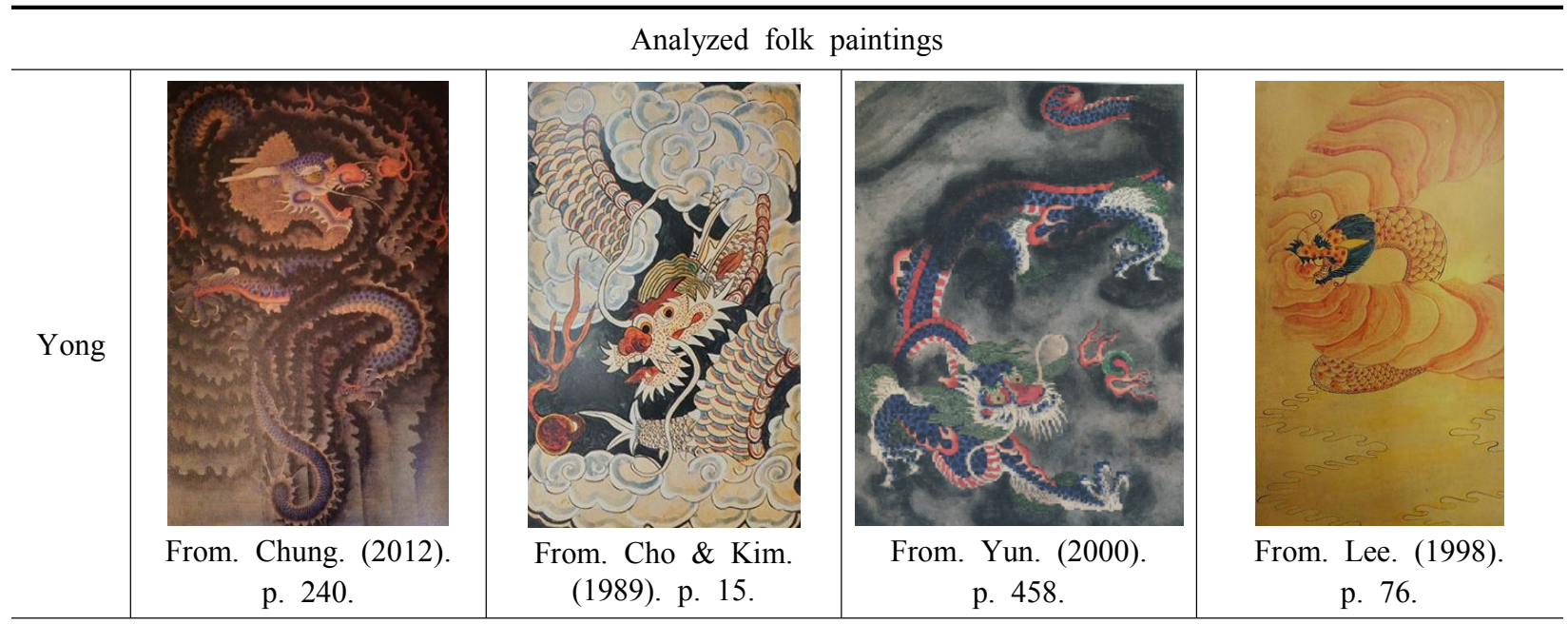


의 눈물을 용루(龍淚)라 하였고, 왕이 앉는 걸상을 용 상(龍床), 왕의 의복을 용포(龍袍)라고 한 것처럼 용은 곧 왕과 동일한 존재로 여겨졌다.

\section{(2) Remarkable talent of transformation}

용은 사령수 중 유일하게 변화, 변신이 가능한 존 재이다. 능수능변(能手能辯)의 존재로 무궁무진한 조 화능력을 갖추고 있어 용에게 신격(神格)을 부여할 수 있는 이유이기도 하다. 용은 자유자재로 모습을 바꿀 수 있을 뿐 아니라 보이게 하거나 혹은 보이지 않게 할 수도 있다. 관자(管子)의 수지편(水地篇)에서 는 '용은 작아지고자 하면 번데기처럼 작아질 수 있 고 커지고자 하면 천지를 덮을 만큼 부풀 수 있고, 높 이 오르고자 하면 구름 위로 치솟을 수 있을 뿐 아니 라, 밑으로 내려가고자 하면 깊은 샘의 밑바닥까지 잠길 수 있다'고 하였다(Heo, 2006). 용은 몸의 크기 를 자유자재로 바꾸면서 물 속 깊숙이 들어갈 수도, 하늘에 치솟을 수도 있는 전지전능한 존재로 변신과 조화의 상징이라 할 수 있다. 변신하는 존재는 무한 한 신비감과 경외심을 일으킨다. 땅과 하늘사이에서 자유로이 변신하는 용은 이러한 이유로 사령 중 으뜸 이라 할 수 있다.

\section{(3) Deity of water as an object of respect}

조선 중종 때 편찬된 '훈몽자회(訓蒙字會)'를 보면, 용을 ‘미르’라 표기하고 있는데, 용의 순수한 우리말 인 '미르'가 물의 옛말인 '밀'과 상통하기 때문에 (Lee, H. H., 2012) 용과 물은 매우 밀접한 관계가 있 다. 물의 많고 적음은 논농사의 성패를 좌우한다. 용 은 논농사 지역에서 물을 주관하는 수신(水神)으로 숭배되어 왔다(Jo, 2006). 이러한 이유로 삼국시대부 터 조선시대까지 가뭄이 들면 용 그림이나 흙으로 빚 은 용의 형상으로 기우제를 지냈다(Chung, 2011a). 농경문화권에서 농사의 풍요는 경제적 안정뿐만 아 니라 태평성대를 의미하기 때문에 용은 풍요를 가져 다주는 존재로 여겨졌다(Kim, 2001).

또한 어업에 있어서도 거친 바다에서 안전하게 많 은 고기를 잡는 것이 중요하기 때문에, 수신은 외경 의 대상이라 할 수 있다. 삼면이 바다인 우리나라의 지형적 특성상 바다는 생명 그 자체이자 동시에 두려 움을 주는 대상이었다. 바다를 관장하는 신이 바로
용왕인데, 용왕제에는 풍어뿐 아니라 바다에서 발생 하는 여러 사고를 예방하려는 기원이 담겨 있었다 (Kim, 2001). 이처럼 수신으로서 용은 우리 민족의 생업과 밀접한 존재로 생명을 길러주는 존재이자 생 명을 앗아갈 수도 있는 경외의 대상이었다.

\section{3) Iconographical interpretation; Reverence for} transcendent power

용은 초월적인 힘을 지닌 존재로 사령 중 유일하게 변신의 능력을 지니고 있다. 변신은 곧 몸으로부터의 해방을 의미하며 자신의 존재가 본래 세계에서 뿐 아 니라 타 세계로 무한히 확장될 수 있음을 의미한다. 인간은 절대 행할 수 없는 변신의 능력을 지닌 존재 로 신적 경지에 도달하고자 하는 인간의 욕망을 대변 한다.

인간은 자력으로 문제 해결이 불가능하다고 판단 될 때 초월적인 힘을 믿으며, 그 힘을 통해 문제를 해 결하고자 한다. 용은 자연에 대한 인간의 공포심리가 결합되어 초월적 실체로 형상화되고 관념화된 상상 의 현실적인 영물로 인식된다(Lee, D. C., 2005). 사 람들은 제의나 기도를 통해 초월적인 힘과 접촉해서 어려움을 극복하고 소원을 성취하고자 한다. 종교현 상학자인 반 델 레에우(Gerardus van der Leeuw)는 종교의 근본조건으로서 '비범한 것'에 대한 경외감을 지적하면서, 이는 곧 놀라운 힘에 의한 것이라 하였 다(Park, 2005).

동양의 종교에서도 마찬가지로 비범함과 놀라운 힘에 대한 경외와 찬양을 발견할 수 있다. 이는 우리 나라 용 문화와 관련이 깊은 불교적 관점에서 볼 때, 감응(感應)의 개념에서 찾아볼 수 있다. 감응은 중생 의 감(感)과 부처의 응(應)이 서로 통하여 불심이 중 생의 마음 가운데 들어가고 서로 소통하는 것을 말한 다. 감응은 초월계와 현실계의 모든 경계가 허물어질 때 펼쳐지는 조화의 아름다움이다(Park, 2005). 그런 데 감응이라는 소통의 기제에는 반드시 '기이한 사 건'이 수반되며, 성스러움을 내포하게 되는데, 이는 신령함이 만물에 감응하여 나타나는 것이기 때문이 다.

이처럼 용은 초월적인 힘을 지닌 강력한 신앙의 대 상이라 할 수 있다. 역동적인 권능의 상서로운 존재 로 힘과 권력의 메카니즘에 있어 최상의 위치에 존재 
하며, 인간의 한계를 벗어나 초월자적인 능력을 꿈꾸 는 집단적 무의식이 투영된 대상이라 할 수 있다.

\section{Bonghwang(鳳凰)}

\section{1) Pre-iconographical description}

봉황은 상상의 새로 새들의 우두머리로 여겨졌다. 형태는 기록에 따라 다소 차이가 있는데, 가장 오래 된 동양의 자전(字典)인 이아(爾雅)에 의하면 “닭 머 리, 제비 턱, 뱀 목, 거북 등, 물고기 꼬리의 모양이고, 오채색(五彩色)에 높이가 6척이 넘는다"고 하였다 (Chung, 2012). 설문해자(設文解子)에서는 “봉황의 머 리 앞쪽은 기린의 수컷, 뒤쪽은 사슴, 몸은 뱀, 꽁지는 용과 같은 비늘이 있고, 등은 귀갑(龜甲), 턱은 제비, 부리는 닭과 같다"고 하였다(Yun, 2012). 이처럼 봉 황은 새의 형상에 짐승과 물고기가 합쳐진 모양으로, 맹금류(猛禽類)와 주작(朱雀)의 특징이 함께 나타난다 (Kim, J. M., 2009).

민화에서는 꼬리가 길며 닭이나 공작새와 비슷한 형상으로 많은 경우 암수가 한 쌍으로 그려진다. 봉 황이 오동나무에 깃을 틀고 대나무 열매를 먹고 산다 는 전설로 인해 오동나무나 대나무가 같이 그려진 경 우가 많고, 상서로운 기운을 강조하기 위해서 태양이 나 영지 등이 함께 그려지기도 한다(Heo, 2006) (Table 3).

2) Iconographical analysis

\section{(1) Symbol of a king}

봉황은 용과 함께 군왕을 상징하는 영물이다. 덕망 있는 군자가 천자의 지위에 오르면 나타난다고 하는 봉황은 오색(五色)의 빛에 오음(五音)의 소리를 낸다 고 한다(Heo, 2006). 용과 봉황의 서열을 매길 때 용 을 상위에 두어 천자의 상징으로 삼고, 봉황을 황후 나 천자에 사대하는 제후의 상징으로 썼다(Yun, 2012). 봉황은 특히 새 중의 왕이자 큰 새를 상징한 다. 이는 큰 새가 날 때 바람을 일으킨다고 하여 봉 (鳳)과 황(風)이 같아졌고, 고음(古音)에서 凰(huáng)

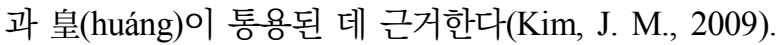
봉황은 조선시대에 궁궐의 연회에서 봉황음(鳳凰吟), 봉래의(鳳來儀)와 같은 무용의 주인공으로 등장했는 데, 이는 봉황이 성군을 송축하는 의미로 사용된 예 라 할 수 있다(Heo, 2006).

\section{(2) Sun worship}

민화에서 봉황은 대부분 태양과 함께 그려진다. 봉 황의 어원에서 볼 때 ‘황(皇)'으로 통용된 ‘황(凰)'이 태양을 의미하게 된 것은 고음(古音)에서 '皇(huáng)' 과 '光(gung)'이 서로 통해 광조(光鳥), 즉 태양조(太 陽鳥)로 인식되었기 때문이다(Kim, J. M., 2009). 고 대로부터 태양은 하늘 높이 걸려 있는 신비한 존재였 으며, 저녁에 지면 아침에 다시 떠오르기 때문에 재 생과 불멸을 상징하였다. 당시 인류는 하늘로 비상하 는 능력을 지닌 새를 태양을 대신할만한 신물(神物) 로 여기게 되었고, 새를 태양의 화신, 상징물로 표현

<Table 3> Analysis object of folk paintings on Bonghwang

\begin{tabular}{|c|c|c|c|c|}
\hline & & Analyzed folk $p$ & ngs & \\
\hline Bonghwang & $\begin{array}{c}(25) \\
\text { From. Lee. (1998). } \\
\text { p. 83. }\end{array}$ & $\begin{array}{l}\text { From. Cho \& Kim. } \\
\text { (1989). p. } 155 .\end{array}$ & $\begin{array}{c}\text { From. Yun. (2012). } \\
\text { p. 106. }\end{array}$ & $\begin{array}{l}\text { From. Lee. (1998). } \\
\text { p. 87. }\end{array}$ \\
\hline
\end{tabular}


했다(Wu \& Roh, 2014). 이처럼 조양봉황도(朝陽鳳凰 圖)는 태양숭배사상과 조류숭배사상이 결합되어 나타 난 것이라 할 수 있다(Kim, 1997).

\section{(3) Symbol of nobility and integrity}

봉황은 청렴과 고결의 표상이다. 봉황과 관련한 속 담에서 '닭의 새끼 봉되랴', '닭이 천이면 봉이 한 마 리 있다’라는 표현처럼, 닭이 평범함을 상징한다면 봉황은 고결하고 빼어난 것을 상징한다(Yun, 2010). 또한 봉황은 천리를 날아 배가 고파도 조를 쪼아 먹 지 않는다. 봉황은 대나무 열매만 먹으며 오동나무에 만 앉는 청렴하고 고귀한 군자와 같은 새이다. 이러 한 이유로 봉황은 유교문자도 중 '염(廉)' 자의 대표 적 상징물로 내세워지기도 한다(Chung, 2012).

3) Iconographical interpretation : Psychic in the sky

봉황은 모든 새들의 왕이자 하늘 위의 영매(靈媒) 라 할 수 있다. 새는 인간은 할 수 없는 하늘을 나는 행위를 할 수 있으며, 땅과 하늘의 공간이동이 가능 한 존재이다. 고대에는 하늘과 땅 사이를 자유롭게 날아오르는 새를 영물(靈物)로 여겨 천상의 안내자이 자 영혼 승천의 사자(使者)로 보았다(Chun, 2003). 삼 국지의 위지동이전 진한조(辰韓條)에는 '장례 시 큰 새의 깃털을 넣어 죽은 이의 영혼이 하늘로 날아가게 한다'는 기록이 있다(Kim, 2004). 비슷하게 조선후기 의 세시풍속집인 『동국세시기(東國歲時記)』와『경도 잡지(京都雜志)』에 고고매가 소개되어 있다. 이는 정 월 대보름에 거위의 앞가슴 솜털을 명주실에 매어 달 리면서 바람에 날리는 놀이를 말하는데, 몽골어로 고 고매가 바로 봉황을 의미한다. 이를 통해 볼 때 봉황 은 동양 문화권에서 인간세상을 벗어나 하늘을 향해 날아가고자 하는 인간의 욕망이 투영된 대상이다.

이처럼 봉황은 하늘과 인간세계를 잇는 천명의 전 달자이자 실행자이다. 중국의 천지우주론에 의하면, 우주 생성의 처음에 혼돈의 무분별한 상태에서 하늘 과 땅이 분리되면서 공간이 생겼고 동시에 시간의 흐 름을 통해 모든 존재가 생겨났다고 본다. 하늘과 땅 의 배치에 따라 공간과 시간이 생기고 그 질서에 따 라 모든 만물이 생겨나게 된 것이다(Lee, Choi, \& Shin, 2005). 설문해자(設文解子)에서는 하늘을 “顛也,
地高無上, 從一大' 라고 하여 더 이상 위가 없는 꼭대 기이자 지극히 높아 그 이상이 없는 최고의 존재, 절 대적 무한자(無限者)로 보았다(Lee et al., 2005). 이처 럼 봉황은 하늘과 인간을 이어주는 매개자로 천상에 서 지상으로, 지상에서 천상으로 영혼을 나르는 전달 자라 할 수 있다.

\section{Shingoo(神龜)}

\section{1) Pre-iconographical description}

신구는 신령스러운 거북으로 실재하는 동물인 거 북의 모습을 토대로 하여 네 개의 발과 등껍질을 지 닌 갑충(甲蟲)의 형상을 보인다. 민화에 표현된 신구 는 신격화된 모습으로 나타나 얼굴이 용머리와 같은 벽사귀면상(辟邪鬼面像)을 하거나 입에서 서기(瑞氣) 를 내 품고 있는 상서로운 모습도 보인다. 바다 속의 파도와 물고기와 함께 그려지거나 연꽃을 배경으로 그려지기도 한다(Table 4).

\section{2) Iconographical analysis}

\section{(1) Fortune prophecy}

예부터 거북의 등을 불에 태워 갈라지는 것을 보고 점을 치는 것을 귀복(龜卜)이라 하는데, 귀복은 고대 사회에서부터 점복의 하나로 전해진다(Kim, 2001). 하나라 우 임금이 치수할 때 낙수(洛水)에서 나온 거 북 등의 점으로 된 무늬를 보고 천지 변화의 기틀을 깨닫고 이를 그림으로 그려낸 것이 낙서(洛書)인데, 여기서 음양(陰陽)의 세계관을 토대로 한 팔괘가 비 롯된 것으로 보기 때문에(Kim, 1997) 신구는 우주를 상징하며 길흥을 예지하는 예언자적 존재라 할 수 있 다.

\section{(2) Being of longevity and immortality}

만년 이상을 산다고 전해지는 신구는 오래 살기 때 문에 신령스럽고 길흥을 알 수 있다. 자신을 보호할 수 있는 껍질을 갖고 있으며, 완만한 호흡과 영양분 을 체내에 보존할 수 있는 습성으로 인해 장수나 불 사의 상징으로 여겨진다. 등껍질은 하늘의 지붕을, 배 의 껍질은 땅을 나타내므로 상하의 껍질이 천지음양 의 힘을 나타내어 수명과 우주를 상징하기도 한다 
<Table 4> Analysis object of folk paintings on Shingoo

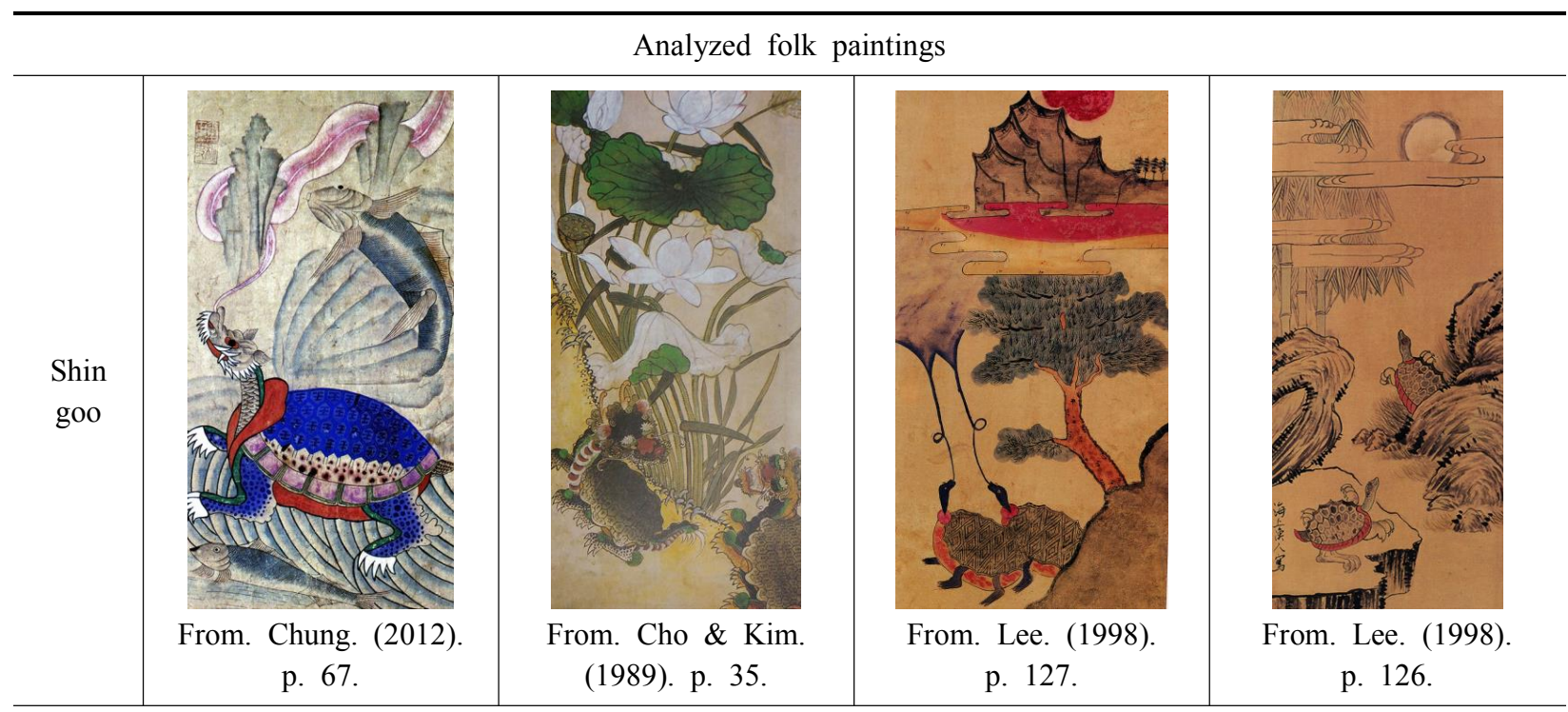

(Yun, 2012). 왕의 인보나 옥새, 인장 손잡이를 거북 으로 형상화한 것을 귀뉴(龜紐)라 하는데, 여기에는 권세가 길이 이어질 것을 기원하는 소망이 담겨 있다 (Kim, 2001).

\section{(3) Envoy of Deity}

신구는 신의 뜻을 전달하는 전달자로 나타난다. 수 로신화의 '구지가(龜旨歌)'에서는 왕을 보내주겠다는 하늘의 뜻을 알려주는 상서로운 동물로 그려지며, 신 라 성덕왕 때 납치 당한 수로부인을 구하기 위한 노 래인 '해가(海歌)'에서는 용의 뜻, 즉 하늘의 뜻을 전 달하는 존재로 그려진다(Kim, 2001). 고려 말의 문인 이색(李穑)의 시에서 “멀리 용 그림을 생각하니 물위 에 띄어 있는데, 낙수의 거북, 하늘이 내린 것, 왕가를 상서롭게 하네. 스스로 신선의 뒤에 뚜렷이 나타난 뒤로 문득 산 속에 들어가 날마다 편안히 놀았네.” 라 고 하였다(Sim, 2004). 이처럼 신구는 신의 사자이자 신선의 영물로 전해진다.

\section{3) Iconographical interpretation; Organic view of} the world

신구는 사령 중 유일하게 거북이라는 실존 동물에 상상의 요소가 결합된 존재이다. 예기(禮記)의 예운 (禮運) 편에 “거북을 가축으로 여기므로 인간의 정을 잃지 않는다"고 하였듯이, 신구는 영묘한 거북으로 인간을 가장 잘 이해하는 신령스러운 동물이자 천인
(天人)과 소통할 수 있는 존재로 여겨졌다(Jung, 2002).

거북으로 점을 치는 행위 속에는 동양의 전통적인 우주 모형과 천지인 삼재에 대한 원형적 사유가 내재 되어 있다(Jung, 2002). 사라 알란(Sara Allan)은 거북 의 형상을 공간적 측면에서 우주의 모형으로 보았다. 즉, 거북의 등껍질은 하늘처럼 둥글어 표면에 별자리 가 나타나 있고 배는 평평하여 땅의 모습을 상징한다 고 보아(Yun, 2010), 하늘은 둥글고 땅은 네모났다는 천원지방(天圓地方)의 중국 고대의 우주관을 거북의 형상에서 찾았다. 유옥건(劉玉建)은 거북의 등은 하늘 을, 배는 땅을, 머리는 인간을 상징한다고 보아 거북 이 우주의 중요한 구성요소인 천지인(天地人)의 형상 을 모두 포괄하고 있으므로 우주의 모형이 될 수 있 다고 하였다(Jung, 2002).

신구는 수륙양생의 생태적 특성을 보이며, 음양의 조화를 토대로 한 유기체적 세계관을 보여준다. 석명 (釋名)에서 거북은 기(氣)의 길흥을 안다고 하였고, 귀 책열전(龜策列傳)에서도 거북은 기를 행할 줄 안다고 하였다(Jung, 2002). 회남자(淮南子)에서는 우주 만물 을 모두 기를 바탕으로 설명하면서 최초의 원기(元 氣)에서 천지가 생겨나고, 천지에서 음양의 기운이 분 화하였다고 하였다. 음양은 밝음과 어둠처럼 서로 대 립되는 성질의 것인데, 음양사상에서는 상반(相反)과 응합(應合)의 논리가 함축되어 있어 서로 반대되지만 상호의존하면서 발전해 간다고 보았다. 이러한 세계 
관에서 인간과 자연은 '기'라는 동질적 구성요소로 이루어져 있기 때문에 평등한 하나의 거대한 유기체 적 구조를 이루게 된다(Kim, 2008).

또한 신구가 지닌 예지력은 인간의 유한한 수명과 는 비교가 안 될 정도로 장수하는 신비로운 특성과도 관련되며, 이는 곧 우주의 영원함을 상징한다. 신구는 스스로가 우주의 모형과 같은 존재로 자연계인 천 (天)과 인(人) 사이에서 서로 감응하고 교류하는 유기 체적 세계관을 토대로 천인합일(天人合一)의 사상을 보여준다.

\section{Kirin(麒麟)}

\section{1) Pre-iconographical description}

땅 짐승을 대표하는 상상의 동물로 수컷을 기(麒), 암컷을 린(麟)이라 한다. 전한(前漢) 말의 역전(易傳) 에서는 "기린은 몸이 사슴과 같이 크고 네 다리는 소 발굽이고 갈기는 말과 같고 등 털의 빛깔은 5 색이고 배의 털은 황색"이라고 했다(Lee, 2000). 사슴 몸에 소 꼬리와 뿔을 지닌 모습이나, 말의 몸체와 유사하 거나, 혹은 용의 얼굴에 용 비늘이 추가되기도 한다. 기린은 실재하지 않는 상상의 동물이므로 형태에 대 한 다양한 기록이 존재하는데, 여러 기록과 도상에서 나타나는 공통적인 사항은 뿔과 소의 꼬리를 가진 짐 승이라는 것이다(Yun, 2010). 조선시대 기린의 형태 는 주로 말의 몸에 용의 비늘을 더하거나, 용의 얼굴 인데 네 발 달린 짐승의 모습으로 나타나며(Lee,
2000), 민화에서는 부귀의 상징인 모란, 오동나무, 해, 구름무늬 등과 함께 표현되는 경우가 많다(Table 5).

\section{2) Iconographical analysis}

\section{(1) Divine benign animal}

기린은 천년을 살지만 거의 눈에 띄지 않는다. 시 경(詩經)에는 '발이 있는 동물은 차기 마련이고, 뿔이 있으면 뿔로 공격하는데, 유독 기린만 그렇지 않으니 이는 어진 성품 때문'이라 하였다(Yun, 2010). 이마에 뿔이 하나 돋아 있지만, 그 끝에 살이 있어 다른 짐승 을 해치지 않으며, 생물을 아껴 풀도 밟지 않는 매우 인자한 동물로 그려진다(Kim, 1997). 이처럼 기린은 유순하며 다른 동물에게 해로운 짓은 절대 하지 않 아, 어질 인(仁)과 평화를 상징한다. 기린의 출현은 어 진 임금이 나타날 징조로 여겨지며, 기린이 나타난 뒤 공자가 탄생하였다고 전해진다(Lee, I. S., 2005).

\section{(2) Symbol of talent and honor}

기린은 재주와 능력을 갖춘 인재를 의미하며, 어진 성품과 함께 온갖 땅 짐승의 영장이라는 점에서 재주 와 능력을 갖춘 걸출한 인재를 기린아(麒麟兒)라고 하 였다(Yun, 2012). 또한 전한(前漢)의 무제(武帝)가 큰 공을 세운 위대한 공신들의 얼굴을 걸어 두는 기린각 (麒麟閣)을 세운 이래로 이곳에 오르는 것이 관직 최 고의 영예로 여겨졌다(Yun, 2010). 우리나라의 경우 도 신라시대에 이미 기린각이 있었으며, 고려, 조선시

$<$ Table 5> Analysis object of folk paintings on Kirin

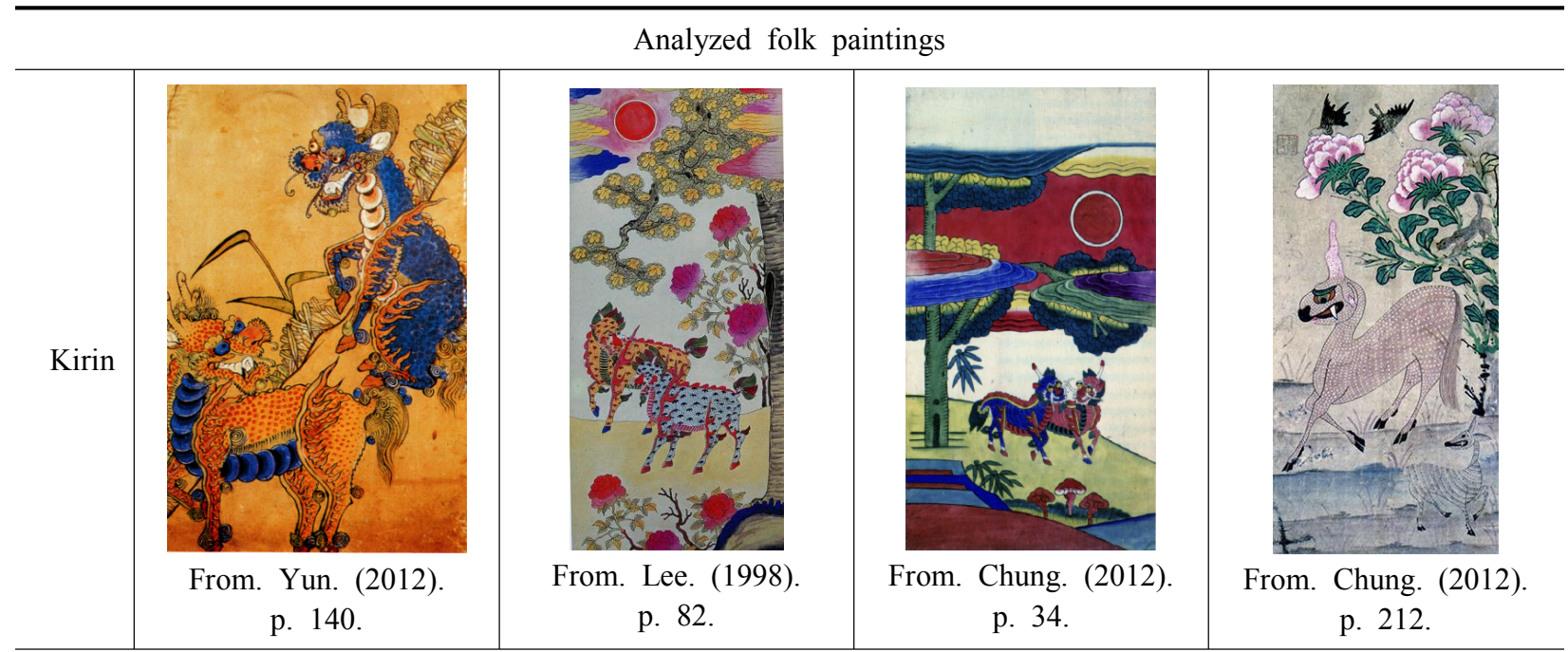


대의 사서에서도 자주 등장하였다. 기린각에 걸린 초 상화는 곧 권력의 중심부에 있음을 의미하였고(Lee, 2000), 뛰어난 공적이나 최고의 영예를 의미하게 되 었다.

\section{(3) Mediator of sky and earth}

기린은 사후세계의 수호자이자 하늘과 땅을 연결 시켜주는 사자로 나타난다. 기린은 중국 한나라 때의 소설인 한무제내전(漢武帝內傳)에서 불사의 신인 서 왕모 일행이 타고 있었던 동물이기도 하다. 또한 고 분미술에서 기린의 위치가 천상세계를 묘사한 천정 과 현실을 묘사한 벽면의 중간에 위치해 있는 점에서 하늘과 땅의 매개자 역할을 하고 있음을 보여준다 (Lee, 2000). 우리나라의 경우, 고려 말 조선 초 문인 권근(權近)의 문집에서 기린굴이 선인이 사는 곳으로 묘사되었고, 조선의 여류문인 허난설헌의 글 '유선가 (遊仙訶)'에 신과의 접신(接神)을 위한 동물 중 하나로 표현되었다.

3) Iconographical interpretation; Expression of confucian ideology

기린은 유교의 태두인 공자에 자주 빗대어 표현되 며, 유교적 덕목인 덕과 인의 상징으로 여겨진다(Yun,
2010). 공자가 춘추(春秋)를 저작할 때 중국 노나라의 애공(哀公)이 기린을 잡았다는 이야기를 듣고 자신의 운명을 예감해 크게 상심하고 절필하였으며, 두 해 후 별세하였다고 전한다(Lee, 2000). 이처럼 기린은 공자의 상징이자 인수(仁獸)로 유교를 대표하는 상징 물이다. 맹자는 '기린은 달리는 동물 중 으뜸이다. 태 산이 모든 산의 으뜸인 것처럼 사람에 있어서도 성인 의 출현과 같은 것이다. 이는 공자만한 성인이 없었 음을 말한다'라고 하여 공자와 기린을 함께 언급하였 다(Lee, 2000). '사기(史記)'에 의하면 공자가 태어났 을 때에도, 죽을 즈음에도 기린이 나타났다고 전해진 다.

살아있는 생물은 밟지 않는다고 전해지는 기린은 공자가 인간이 실천해야 할 가장 중요한 덕목으로 강 조한 인(仁)을 상징한다. 인은 ‘사람 인(人)' 자와 ‘두 이(二)' 자가 결합된 글자로 두 사람 사이의 바람직한 인간관계의 의미를 말한다(Jung, 1997). 공자에 의하 면 인은 이기적 욕구를 자제하면서 보편타당한 예에 이르는 것으로 소아(小我)를 버리고 대아(大我)로 돌 아가는 것이자 인간을 인간답게 하는 본성이라 할 수 있다.

동양적 가치관에서 볼 때 우주는 천지인의 삼재(三 才)로 구성되는데, 주역의 설괘전(說卦傳)에 의하면

$<$ Table 6> Iconological analysis on four auspicious animals

\begin{tabular}{|c|c|c|c|c|}
\hline & & $\begin{array}{l}\text { Pre-iconographical } \\
\text { description }\end{array}$ & $\begin{array}{l}\text { Iconographical } \\
\text { analysis }\end{array}$ & $\begin{array}{l}\text { Iconographical } \\
\text { interpretation in } \\
\text { deeper sense }\end{array}$ \\
\hline Yong & $\begin{array}{l}\text { A leader of } \\
\text { animals with } \\
\text { scales }\end{array}$ & $\begin{array}{l}\text { Mixed animal shape (snake } \\
\text { head, antler, rabbit eyes) }\end{array}$ & $\begin{array}{l}\text { - Symbol of royal authority } \\
\text { - Remarkable talent of } \\
\text { transformation } \\
\text { - Deity of water as an object of } \\
\text { respect }\end{array}$ & $\begin{array}{l}\text { Reverence for } \\
\text { transcendent power }\end{array}$ \\
\hline $\begin{array}{l}\text { Bong } \\
\text { hwang }\end{array}$ & $\begin{array}{l}\text { A leader of } \\
\text { animals with } \\
\text { feathers }\end{array}$ & $\begin{array}{l}\text { Mixed appearance of animal } \\
\text { and fish with bird shape }\end{array}$ & $\begin{array}{l}\text { - Symbol of a king } \\
\text { - Sun worship } \\
\text { - Symbol of nobility and integrity }\end{array}$ & Psychic in the sky \\
\hline $\begin{array}{l}\text { Shin } \\
\text { goo }\end{array}$ & $\begin{array}{l}\text { A leader of } \\
\text { animals with } \\
\text { shells }\end{array}$ & $\begin{array}{l}\text { Dragon-face strange } \\
\text { appearance with turtle shape }\end{array}$ & $\begin{array}{l}\text { Fortune prophecy } \\
\cdot \text { Being of longevity and } \\
\text { Immortality } \\
\text { - Envoy of deity }\end{array}$ & $\begin{array}{l}\text { Organic view of } \\
\text { the world }\end{array}$ \\
\hline Kirin & $\begin{array}{l}\text { A leader of } \\
\text { animals with } \\
\text { furs }\end{array}$ & $\begin{array}{l}\text { One-horned, furred animal } \\
\text { with hoof and mane of horse }\end{array}$ & $\begin{array}{l}\text { - Divine benign animal } \\
\text { - Symbol of talent and honor } \\
\text { - Mediator of sky and earth }\end{array}$ & $\begin{array}{c}\text { Expression of } \\
\text { confucian ideology }\end{array}$ \\
\hline
\end{tabular}


인간의 본성인 인의는 천의 본성인 음양과 지(地)의 본성인 강유(剛柔)에 대응한다고 하였다. 유교에서 인 간다움의 조건이 되는 인간의 덕성은 결국 천지의 본 성에 근거하여 확립된 것이다(Lee, 2001). 유교적 관 점에서 볼 때 인간은 우주 자연의 주체이자 객체이 며, 하나의 소우주로서 우주 자연 그 자체이자 그것 의 일부라 할 수 있다(Lee, 2001).

민화에 나타난 사령수의 도상해석학적 분석내용을 표로 정리하면 〈Table 6〉과 같다. 분석 결과, 용은 도 상학적으로 왕권의 상징, 변신의 조화, 숭배의 수신 (水神)으로 나타났고, 도상해석학적으로 분석하면 초 월적 힘에 대한 숭앙으로 볼 수 있다. 봉황은 군왕의 상징, 태양숭배 사상, 고결 - 청렴의 표상으로 종합하 면 하늘 위의 영매로 고귀하고 절대적인 무한자라 할 수 있다. 신구는 미래의 예언자, 장수 - 불사의 존재, 신의 사자로 볼 수 있으며, 종합하면 유기체적 세계 관의 현현(顯現)이라 할 수 있다. 기린은 상서로운 인 수(仁獸), 재능의 상징, 하늘과 땅의 매개자로 도상해 석학적으로 해석하면 유교적 이데올로기의 표현으로 볼 수 있다.

\section{N. Conclusion}

본 연구는 민화에 등장하는 사령수에 대한 도상해 석학적 분석을 통해 동양 문화권에 내재되어 있는 상 상 동물의 상징체계를 밝히고자 한 것이다. 파노프스 키의 도상해석학은 작품에 나타나는 시각적 징후를 통해 미적 대상의 심층에 내재되어 있는 의미를 밝히 는데 유용하므로 분석방법으로 사용하였다.

파노프스키의 도상해석학에 의하면, 전 도상학적 단계는 조형적 형태 분석을 통해 표현의미를 파악하 는 단계로 예술적 모티프를 나열하는 단계이다. 도상 학적 분석 단계는 이차적, 관습적 주제에 대한 인식 에 해당되며, 문헌기록에 대한 지식을 토대로 작품의 주제와 상징, 알레고리를 파악하는 단계이다. 마지막 으로 도상해석학적 해석 단계는 종합직관을 통해 본 래의 의미내용이나 문화적 징후의 역사를 밝히는 것 이다. 파노프스키의 도상해석학에 의하여 사령수를 분석한 내용을 요약, 정리하면 다음과 같다.

용은 전도상학적 단계에서 보면 날짐승, 들짐승, 물짐승의 복합적인 형태로 여러 동물이 지닌 최대 강
점만을 모은 형상을 보인다. 도상학적으로 권력과 왕 권의 상징, 변화 - 변신의 조화, 농경사회에서 민중의 삶에 지대한 영향을 미치는 숭배의 수신으로 나타났 다. 이를 도상해석학적으로 분석하면 인간의 일상을 장악하면서도 인간적인 범주를 뛰어넘는 강력한 힘, 초월적 힘에 대한 숭앙으로 볼 수 있다.

봉황은 새의 형상을 주로 하면서 짐승과 물고기가 합쳐진 모양으로 큰 새, 새 중의 우두머리를 의미하 여 군왕을 상징하며, 태양숭배 사상과 고결 - 청렴의 표상으로 볼 수 있다. 이를 종합하면 스스로가 고귀 한 존재이자 영혼을 나르는 전달자로 절대적 무한자 와 인간을 연결해 주는 하늘 위의 영매라 할 수 있다.

신구는 실재하는 동물인 거북의 모습을 토대로 용 의 모습이 합성된 형태로 도상학적으로 볼 때 길흥을 예지하는 미래의 예언자, 지혜로운 장수 · 불사의 존 재, 신의 뜻을 전달하는 사자(使者)로 볼 수 있으며, 종합하면 스스로가 우주의 형상을 하며, 음양의 조화 를 토대로 천(天)과 인(人)이 서로 감응하는 유기체적 세계관의 현현(顯現)이라 할 수 있다.

기린은 사슴이나 말의 몸체에 용의 얼굴이 더해진 모습으로 상서로운 인수(仁獸), 재능과 영예의 상징, 하늘과 땅의 매개자의 역할을 하며, 도상해석학적으 로 분석하면 유교의 태두인 공자의 인(仁) 사상을 대 변하기 때문에, 이기적 욕구를 통제하고, 보편타당한 예를 추구하는 유교적 이데올로기의 표현으로 정리 할 수 있다.

본 연구를 통해 얻은 결론은 다음과 같다. 첫째, 사 령수는 인간의 한계, 나약함에 대한 인식과 이를 극 복하고 싶은, 혹은 절대적인 존재에게 의탁하고 싶은 욕망이 반영된 것으로 신화적인 능력을 갖춘 상서로 운 영물을 통해 문제를 해결하고자 한 인간의 희망이 투영된 존재이다. 둘째, 사령수에는 풍어(豊漁), 풍작 (豊作), 장수 등과 같은 직접적이고 통속적인 바램과 개인과 공동체의 안위와 성공을 바라는 현세복락적 가치관이 반영되어 있다. 셋째, 사령수의 도상은 독립 된 양상이 아니라, 상호 공통되거나 서로 복합적인 성향을 보인다. 용은 비늘을 지닌 린충(鱗蟲), 봉황은 새, 신구는 갑충류, 기린은 땅짐승의 우두머리로 각 영역의 최고로서 출중한 능력의 소유자로 특히 용과 봉황은 우두머리로서의 상징적 의미가 크게 나타났 고, 신구, 기린은 신의 사자로서 인간의 바램을 하늘 
에 전달하는 매개자로서의 역할이 공통적으로 나타 났다. 사령수는 스스로가 신과 같은 존재이거나, 신을 매개하는 접신을 위한 존재로 볼 수 있다.

\section{References}

Cho, J.-Y. \& Kim, C.-S. (1989). (朝鮮時代) 民畫: 下 券 [The folk painting of Korea (Vol. 2)]. Seoul: Yekyongsaneopsa.

Chun, J. G. (2003). 한국동물민속론 [Korean animals in folk theory]. Seoul: Minsokwon.

Chung, B. M. (2011a). (무명화가들의 반란) 민화 [Rebellion of an obscure artists, Minhwa]. Seoul: Dahalmedia.

Chung, B. M. (2011b). Iconological origin and change of Korean folk painting "Dragon and Tiger". The Art History Journal, 37, 259-282.

Chung, B. M. (2012). 민화, 가장 대중적인 그리고 한 국적인 [Minhwa, the most popular and Korean]. Paju: Dolbegae.

Four auspicious animals pattern (四靈文). (n.d). In Encyclopedia of Korean Culture. Retrieved November 7, 2016, from http://encykorea.aks.ac. $\mathrm{kr} /$ Contents/Index?contents_id=E0025506

Heo, G. (2006). 허균의 우리 민화 읽기 [Reading our folk paintings: Minhwa]. Seoul: Bookfolio.

Hyun, H. H. (2013). A study on iconographic meaning and symbolism of minhwa: Focusing on ethics munjado. Unpublished doctoral dissertation, Kookmin University, Seoul, Korea.

Iconography. (n.d). In Doopedia. Retrieved July 17, 2016, from http://www.doopedia.co.kr/doopedia/ master/master.do?MAS_IDX=101013000716839 \&_method=view

Jo, H. S. (2006). 우리 신화의 수수께끼 [Riddles of our myth]. Seoul: Hangyeore.

Jo, Y. J. (1997). 서양화 읽는 법 [How to read Western painting]. Seoul: Sakyejul.

Jung, B. S. (2002). The origin of I-ching and divination by burning tortoise shells. Journal of Eastern Philosophy, 31, 171-194.
Jung, J. I. (1997). 유교의 이해 [Understanding of Confucian]. Seoul: Hyungseul.

Kaemmerling, E. (Ed.). (1997). 도상학과 도상해석학. 이론전개-문제점 [Iconography and Iconology: Theories, development, problem] (H. S. Lee, S. D. Noh, J. H. Park, H. Y. Song, \& J. K. Hong, Trans.). Seoul: Sakyejul. (Original work published 1979)

Kang, M.-K. (2015). The shape and perception of Taoist animals in Yusun Literature, Dong-Bang Korean Chinese Literature, 62, 31-61.

Kim, J. D. (2001). (33가지 동물로 본) 우리문화의 상 징세계 [Symbolism of Korean Culture]. Seoul: Dareunsesang.

Kim, J. M. (2004). Phoenix pattern and the Korean's gods of heaven idea. Journal of Korean Cultural History, 21, 135-169.

Kim, J. M. (2009). A study on the relationship between three legged crow(三足烏), Jujak(朱雀) and Bonghwang(鳳凰). The Journal of Korean Historical-forklife, 31, 233-285.

Kim, K.-E. (2009). A study on the development of Korean painting appreciation program for junior high school class using iconography. Unpublished master's thesis, Dankook University, Gyeonggi-do, Korea.

Kim, M.-T. (2008). The aesthetic meaning of fortune telling. Studies in Religion, 52, 127-159.

Kim, Y. J. (1997). 귀신먹는 까치호랑이: 민화를 통 해 본 우리문화의 수수께끼 [The tiger eating a ghost: Riddle of Korean culture through folk paintings]. Seooul: Dulnyouk.

Kim, Y. J. (2015). 민화의 뿌리 [Roots of Korean Minhwa painting]. Seoul: Jayumungo.

Kusano, D. (2001). 환상동물사전 [Dictionary of the monster] (H. A. Song, Trans.). Paju: Dulnyouk. (Original work published 1997)

Lee, D. C. (2005). 한국 용설화의 역사적 전개 [Historical development of Korea Yong folktales]. Seoul: Minsokwon.

Lee, D. C., Choi, J. S., \& Shin, J. G. (2005). 21세기 
동양철학. 60 개의 키워드로 여는 동아시아의 미 래 [21st century oriental philosophy]. Seoul: Eulyoomunhwasa.

Lee, E. J. (2012). Panofsky's iconological interpretation of renaissance dress. Korean Society of Fashion Design, 12(3), 79-96.

Lee, H. H. (2012). 미르: 용에 관한 모든 것 [Mireu: Everything about dragon]. Seoul: Bookbybook.

Lee, I. S. (2005). 온 가족이 함께 읽는 신화상상동물 백과사전 [Mythical imaginary animals encyclopedia]. Seoul: A tree of ideas.

Lee, J. J. (2000). Research on the Qilin 麒麟 Iconography. Unpublished doctoral dissertation, Daegu Catholic University, Gyeongsangbuk-do, Korea.

Lee, J.-W., \& Geum, K.-S. (2008). Iconological interpretation of the fashion of rock stars in the 1960 's. Journal of the Korean Society of Costume, 58(6), 69-84.

Lee, Y. C. (2001). 유교사회학 [Confucian sociology]. Seoul: Yemoonseowon.

Lee, Y. S. (1998). (朝鮮時代의) 民畫 [The folk paintings of Chosun dynasty]. Seoul: Yewon.

Lim, S. (2012). Theoretical examples for art discourses in the age of convergence: W.J.T. Mitchell and Erwin Panofsky. The Journal of Aesthetics and Science of Art, 36, 47-69.

Lim, S.-M. (2012). On some figurative aspects of Korean imaginative animals: Working report. Unpublished master's thesis, Hongik University, Seoul, Korea.

Panofsky, E. (1972). Studies in iconology: Humanistic themes in the art of the Renaissance. New York: Harper and Row. (Original work published 1939) Park, C. M. (2010). 이야기하는 민화 [Talking Korea folk paintings]. Daegu: Dohwawon.

Park, S. J. (2005). Forming discourse of buddhistic divine response: Focusing on the interaction via power. Journal of Korean Oral Literature, 21, 459-486.

Sim, Y. O. (2004). A study on the longevity good fortune symbol image of the ten longevity symbols painting. The Eastern Art, 8, 118-158.

Takerube, N. (2000). 판타지의 주인공들 [The main characters of fantasy] (H. S. Lim, Trans.). Paju: Dulnyouk. (Original work published 1988)

Wu, J., \& Roh, M.-S. (2014). A study on the visual expression of China with respect to sun worship: Focused on bird images. Journal of Korean Society of Design Science, 27(1), 175-196. doi:10.15187/adr.2014.02.109.1.175

Yu, W., Nahm, J.-W., \& Pyo, J.-O. (2015). A study about the meaning of experience education on children's creativity through the imaginative communion between mythology and animals. Semiotic Inquiry, 42, 355-384.

Yun, Y. S. (2000). Korean art book: 민화 II [Korean art book: Folk paintings II]. Seoul: Yekyong.

Yun, Y. S. (2010). 신화 속 상상동물 열전 [A story on imaginary animals in mythology]. Seoul: Korea Cultural Heritage Foundation.

Yun, Y. S. (2012). 민화 이야기 [Tales of Korea folk painting, Minhwa]. Seoul: Designhouse. 